\title{
The Near-Death Experience: Myth or Reality? \\ A Methodological Approach
}

\author{
Michael B. Sabom \\ Emory University School of Medicine
}

Since the publication of Life After Life (Moody, 1975), numerous reports have confirmed the existence and basic pattern of the neardeath experience (NDE) as described by the author of this book. Considerable controversy continues to exist, however, over the interpretation of these near-death accounts. A major portion of this controversy focuses upon one central question: Is the NDE an authentic experience? For the near-death survivor who has encountered an NDE, there is usually little doubt as to the reality of the experience: "That was real. If you want to, I'm perfectly willing for you to give me sodium pentathol ... It's real as hell." 1 For a large segment of the medical and scientific community, however, these experiences are felt to be mental aberrations provoked by the emotional and physiological stresses of the near-death condition: "People who undergo these 'death experiences' are suffering from a hypoxic state during which they try to deal psychologically with the anxieties provoked by medical procedures and talk. ... We are dealing here with the fantasy of death ..." (Blacher, 1979). Thus, a standoff exists between the near-death survivor who insists that his NDE is "real as hell" and leading scientists and physicians who maintain that such experiences are merely a "fantasy of death." If this controversy is to be resolved, some objective means of evaluating the NDE must be found. It is the aim of this paper to present one such means of evaluating this experience in regard to the current controversy over whether, indeed, the NDE is myth or reality.

I first became interested in investigating the NDE after reading Dr. Moody's book, Life After Life, in 1976. My skepticism of Moody's findings prompted me to begin a systematic investigation of these experiences in patients of my own who had survived a close brush with death. Accompanying me in this endeavor was Sarah Kreutziger, then a psychiatric social worker at the University of Florida. One of the goals of this study was to determine whether or not the NDE was an accurate account of a real situation.

The patients we chose for this study had all survived at least one 
episode of unconsciousness and physical near death. Unconsciousness was taken to mean any specific period of time during which a person lost all subjective awareness of environment and self-a condition most commonly referred to in lay terms as "blacking out." Near death, on the other hand, meant any bodily state resulting from an extreme physiological catastrophe, accidental or otherwise, which would reasonably be expected to result in irreversible biological death in the majority of instances and would demand, if available, urgent medical attention. Using systematic interviewing techniques, we questioned these patients about possible recollections from their period of unconsciousness and near death. In addition, we recorded each person's age, race, area of residence, size of home community, occupation, religion, frequency of church attendance, previous knowledge of NDEs, and fear of death and belief in an afterlife both before and after the crisis. Characteristics of the medical crisis were also noted, including the type and location of the event, the estimated duration of unconsciousness, and the method of resuscitation. If details of the medical resuscitation per se were claimed to have been "observed" by the patient, then a comparison was made between the details of the actual resuscitation (as reconstructed from the medical record and/or the testimony of others present at the time) and the patient's own account based on his NDE.

To date, one hundred and sixteen near-death survivors have been interviewed in this study. The mean age of this group is fifty-three years, with a range from seventeen to eighty-six. Seventy-eight of these persons had been resuscitated from a cardiac arrest, twenty from a non-cardiac comatose condition, ten from an intraoperative crisis, seven from a severe accident, and one from a suicide attempt. Seventy-two persons from this group could recall a definite experience that had occurred during the period of unconsciousness. In thirty-six of these experiences, the person claimed to have had a floating sensation "out-of-the-body" during which his own unconscious physical body and immediate surroundings were "observed" from a position several feet above the plane of the physical body. This "out-of-body" sensation was typically described in the following manner: "It was a feeling of height, great distance, a light feeling, like being up in a balcony looking down and watching all this and feeling very detached as though I was watching someone else, like you might watch a movie."2

In attempting to explain this portion of the NDE, physicians and scientists have traditionally begun with the assumption that visual and auditory perceptions are always a direct and indivisible function of the physical body and can, under no circumstances, occur apart 
from the physical confines of brain and body. Using this line of reasoning, proponents of this traditional approach have concluded that any sort of "out-of-body" experience, near death or otherwise, is simply not possible regardless of how "real" it had seemed at the time. Explanations for the apparent contradiction between experiential (i.e., "It's real") and traditional scientific (i.e., "It's simply not possible") assessments of the NDE are then sought to find some physical or psychological bodily mechanism to account for the NDE. Such explanations have included hallucinations, dreams, temporal lobe seizures, physiological derangements (hypoxia, hypercarbia), depersonalization reactions and others.

When I began my study of the NDE, I was convinced that the NDE would readily be accounted for using some traditional scientific explanation. I have searched for such an explanation over the past five years and have not yet found one that is adequate. In recent years I have begun to consider another approach toward explaining the NDE, an approach which holds open the possibility that the perception of an "out-of-body" experience at the point of near death may be accurate, i.e., that it somehow does occur "out-of-body." To test this hypothesis, I am using a scheme similar to the one outlined in Figure 1. According to this scheme, I am critically examining the details of all NDEs that contain descriptions of resuscitative events and am comparing these descriptions to the medical records and/or the testimony of others present at the time of the near-death event. If the details reported from the NDE do not match the known facts in the case, then this would be strong evidence against the claim that an accurate observation of the situation had occurred from an "outof-body" (or any other) location. If, on the other hand, the details from the NDE matched the known facts in the case, several possibilities would arise. If only a general description of the resuscitation was contained in the NDE-such as, "I saw several doctors and nurses standing around my bed doing things to my body"-then this description, although materially correct in its own right, would offer little substantive evidence that the resuscitation had been viewed from an "out-of-body" location. Such a general description could easily be contrived by a nonmedical layman using common knowledge of hospital procedure without invoking any special means of perception.

However, if accurate details of the resuscitation were described by the near-death survivor from his NDE and these details were found to be specific and unique to the situation in question, then something more than "common knowledge" of resuscitation procedure would be demonstrated. If such specific details were present in only one or 


\section{FIGURE I}

DETAILS REPORTED IN THE OUT-OF-BODY NDE

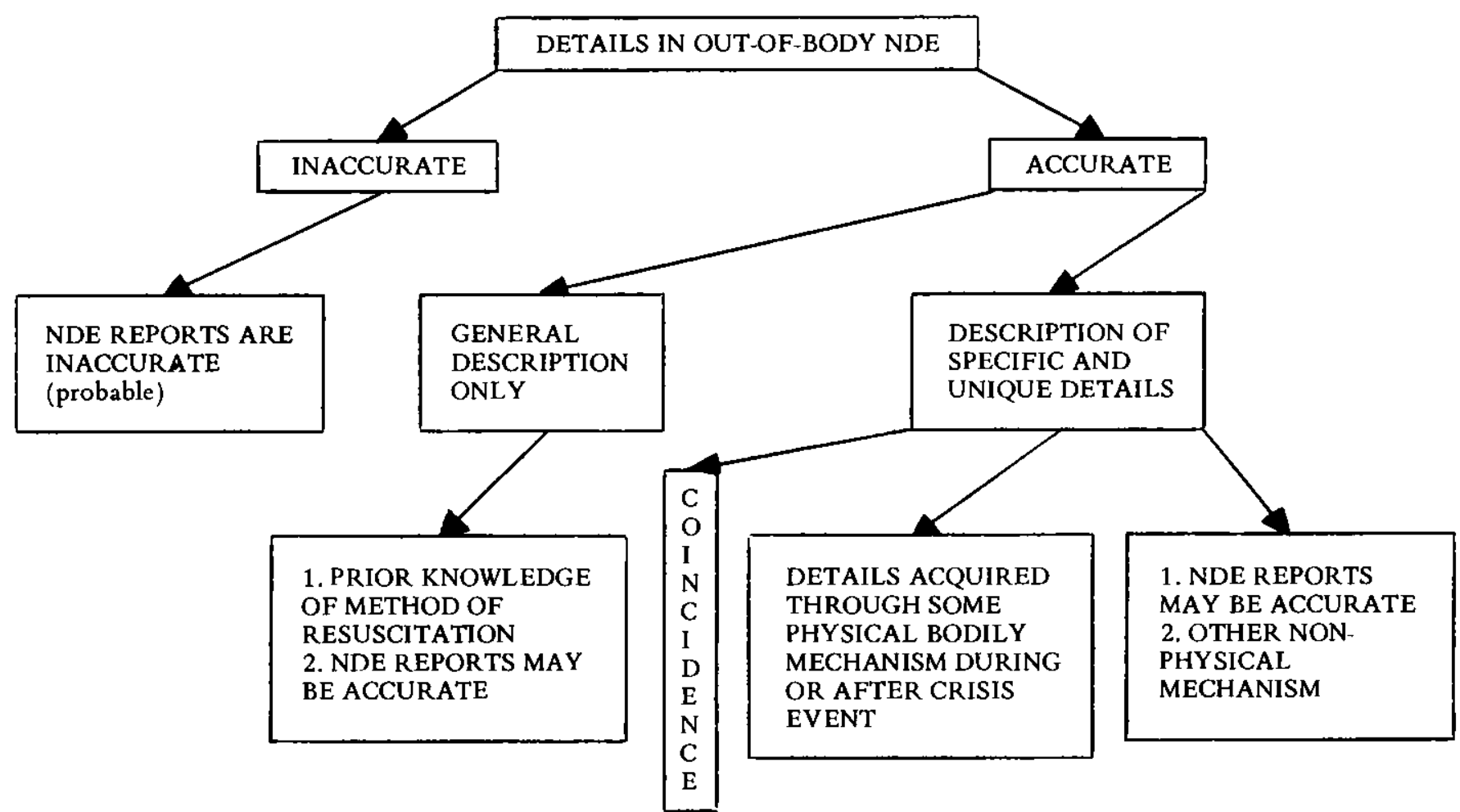


two cases, one might argue that the finding is mere coincidence. If several cases were found, however, coincidence would be unlikely and other possibilities would arise. Could the near-death survivor have acquired the information about his resuscitation through some physical bodily mechanism either during or after his crisis event? For example, could he have caught a physical glimpse of the ongoing procedure at a time when he was not fully unconscious? Could he, while semiconscious, have physically listened to what was being said at the time and then constructed a visual image of the actual situation based on this verbal input? Or could someone (i.e., a doctor or nurse) have explained to him after he had regained consciousness what had occurred during the resuscitation? All such physical explanations for the acquisition of accurate and specific knowledge must be considered first before examining alternative hypotheses.

Suppose, however, that no physical explanation can be foundthat is, the near-death survivor acquired accurate and specific information about his resuscitation that was out of his physical visual field, was not discussed by others present, and was not explained to him following his return to physical consciousness. The possibility would then arise that the information was acquired through some non-physical means such as an "out-of-body" experience.

Consider, for example, the following transcript of an interview I had with Don Knowlton, a respiratory therapist at a neighboring Atlanta hospital. In this interview Mr. Knowlton describes to me the NDE of one of his patients whom he had helped to resuscitate. Many of the details of this man's NDE were verified by Mr. Knowlton. Unfortunately, I was not able to personally interview this patient prior to his death a few days following his cardiac arrest. Thus, this patient is not included in my NDE study. Nevertheless, I present this case as an example of many of the points raised in the foregoing discussion.

(In this interview the $K$ stands for Mr. Knowlton, the $S$ for the author.)

K: I was on the floor working with a patient and heard the code call and realized that the room was across the hall from me and I just sorta ran in. The patient was a 62-year-old Caucasian male and he was on the floor and the nurse was attempting to breathe him. The first thing I did was to start CPR. He was beginning to go bluish. His face was mottled. The nurse was breathing him so I started CPR. He was a post-MI [heart attack]. He had been in CCU [Coronary care unit] about three or four days, I'm not really sure, and he came out of 
there. It had been a mild MI. He was on the floor for routine care and he had a lung problem and we were treating him for that. He had been out of CCU for about a day and a half. Anyways, as I was pumping him, the nurse left the room. She left the room to go get the crash cart, so I started doing bothone man CPR. I must have done it for less than a minute and by that time there were other members of our team there. $I$ continued $C P R$ and the next member of the team started breathing with an $\mathrm{Ambu} *$ bag. By that time the crash cart had come into the room and we had gotten the 100 percent $\mathrm{O}_{2}$ [oxygen] bag off the cart and hooked it up to the wall outlet and were bagging him with 100 percent $\mathrm{O}_{2}$. So I stayed with CPR. As they brought the crash cart in the room, it was behind him possibly a foot or so and to the right. We use an aluminum lock on the bottom of the crash carts that theoretically you can remove if you bend twice like that. The nurse doing it was a student nurse and she was uptight about it and was having difficulty. I saw what was happening so I reached in my pocket and gave her my scissors to put in the lock to twist in between beats. I continued then with CPR for four to five beats, and she handed me back my scissors. At that time the resident [physician] had arrived and took over with normal resuscitation procedure. [We used] a normal black anesthesia mask [to breathe for the patient]. The one we were using was the larger size. He was not obese but was heavy and well nourished. He had an underslung jaw so in order to cover it, we just grabbed the biggest mask we could find which came well above the bridge of the nose almost to the hairline.

S: Was the patient lying on the floor face up?

K: Yes.

S: Was the Ambu bag to the right or left of the patient's head?

$K: \quad$ It can be either way but in this case it was to the right. I was working to the left. I was in on the left side of him. Automatically we bag from the opposite side. . . [The crash cart was] behind his head and to the right and the Ambu bag and part of a therapist, because the therapist was down on her 
knees bagging, was between him and the crash cart.

S: So the mask, bag, and therapist would have obstructed his vision from the crash cart even if his eyes had been open?

K: It would have been beyond the range of peripheral vision. I could tell you he didn't have his eyes open because if we don't have the patient hooked up to a monitor during $C P R, I$ try to watch his face to see if there is any response until somebody gets in and does a femoral artery pulse check and then I start concentrating on that. I was watching his face for the color change and his eyes were closed. It's been my experience in codes [Code 99] that they are rarely open.

S: Right. Mine too.

K: Now I don't say I watched him every second and he could have opened his eyes for a moment without me seeing it. When the doctor came in, he started checking the eyes to see if they were fixed and dilated and I do remember him lifting the eye up. The eyes were not fixed and dilated at that point but they were enlarged. And by then some three or four minutes had passed and I can only gauge roughly in time. It's very difficult to look back and later say it was so many minutes. Well, the resident came in and checked the eyes and then went down and started monitoring the femoral pulse. The nursing supervisor had come in the room and was standing behind the crash cart and was recording. She functioned as recorder. [She is] probably an easily-identifiable woman. She's heavy-set and a good five foot eight or nine inches tall and probably in her late 50's or early 60's. She's very quietnever says a word. She was doing all of the recording. I had been working on him for about fifteen minutes and his staff doctor came in and they had gotten the monitors on him and he was straightlined [no heart beat] except of my pulsing. He was hooked up to the EKG about five minutes into the code I would say. So we stopped and we both watched the monitor and it was flatlined. The resident had me stop for about thirty or forty-five seconds. They had already gotten the IV in. Anyway, they stopped for about thirty seconds, I guess. It seemed like a long time so I assume it was thirty seconds, you know. He was straightlined so I went back to pumping. I pumped for another, possibly, four or five minutes. There 
were some medications given and I don't really remember what they were. I usually shut all that out and concentrate on time. He had me stop again and then we were getting a little bit of ventricular fib-[a weak and ineffective heart rhythm]-just a squiggly line. So I went back to pulsing [CPR] and there were more medications given and we began to get a beat. I thought I felt a beat. He was being perfused apparently because in this process we drew an arterial blood gas. It came back and I remember the blood gas-his $\mathrm{PO}_{2}$ was somewhere around 180 or so. We were over-ventilating him obviously. The $\mathrm{pH}$ [of the blood] was sitting down around 7.25 or so. I began to feel a little beat and I told the resident at the time so I stopped. At that point we began to get a normal sinus rhythm. We got a few ectopic-type beats [extra heart beats] and then we got a normal sinus rhythm. His blood pressure at that point with a Doppler [device used to measure low blood pressures] was about 80 or 90 over doppler. Then they started dopamine [a cardiac stimulant]. At that point I quit CPR but stood right there ready. So we got his blood pressure up to 110 over 60 , somewhere in thereI don't really remember. I remember it was stable enough so we could move him. He was still being bagged but we had elected not to intubate him at that point which is contrary to the usual. Normally we just slip it [the intubation tube] right in [the lung]. He had a slightly underslung jaw and we started at one point to intubate but the position he was laying in, it was hard to get around behind him. So he had an underslung jaw and when we put the laryngoscope [instrument used to insert intubation tube into lungs] down, it was very difficult to visualize the [vocal] cords, so we just came out and went back to bagging [ventilating with Ambu bag]. And then we began to get intermittent voluntary breaths, so the therapist elected not to pursue intubation. We never cardioverted him, which is again unusual. We got his blood pressure up and he was breathing on his own and on the monitor his pulse looked fairly stable. So we rolled a sheet under him and picked him up to put him on the bed to transport him to CCU. I stayed with him for another couple of minutes. I transported him on down to CCU. The following day I went in and was talking to him and I asked him how he was feeling. He felt great and wanted to get out of $C C U$. After a couple of minutes of conversation, he looked at me and said, "You were the fellow who was working on me yes- 
terday." Well, I said I was there. But there was, gosh, four of the RT staff [respiratory therapy] plus the nurses and nursing supervisor and resident. He said, "You were working on me because I remember seeing you." I said, "Well, that's good, but I don't remember you having your eyes open at all." He said, "No, no. When I was up above." I said, "Okay. What do you mean 'Up above'?" He said, "Well, this is going to sound a bit weird to you but you're a little bit older and look like you've been around and maybe you won't think I'm nuts. So I gotta talk to somebody." So I said, "Talk." Then he described this feeling that he had had and what he had seen. What he described to me was no sense of fear, no sense of panic. He said he felt just sorta light and comfortable. He realized that as he was looking that he was higher than the people around him and he was looking down on his own body wondering what all the fuss was about. The only thing he felt was a great sense of relaxation, sorta at peace without pain. Then $I$ asked him if he had seen anything in particular and he sorta laughed and said, "Yes. I remember the trouble you had getting that lock off of the mechanics cart." And our crash carts do look like the standard auto mechanics tool box. He said "I remember the trouble the nurse had getting the lock off of that mechanics cart. You handed her your scissors," or no, he said, "You handed her something." And I said, "Yea, my scissors." He said, "Yea, whatever. But then she got it open." I then said, "Well, how did you feel? I'm curious about all of this." He said, "Well, I just felt comfortable and just wished that you people would just relax and be happy because I was happy and comfortable and didn't want to be bothered." Then he said, "Oh. I remember that big heavy nurse standing over behind the crash cart writing things down on a clipboard and she had a stopwatch. I was wondering what she was worried about the time for because I wasn't going anyplace." I wasn't aware that she had a stopwatch. I wasn't even aware of this myself. I later asked her and she said, "Sure. I always keep one up at the comer of the clipboard because there are no code clocks in the rooms." I wasn't even aware of it myself because normally being down with the patient I don't look up and around to see what's happening. Then he said he felt like he just wished people would leave him alone and that he had no sense of fear. Until that time he had had a sense of fear of dying or a sense of fear with the pain. He said after that he had no fear of it. I 
asked him if he realized death at that time and he said the word death had never occurred to him. He just felt comfortable and knew it was all over. A sense of finality. But the word death didn't occur to him. Then he said he felt like he had to come back to his body or put himself back together is the way he put it. That was all he remembered.

S: Had he observed other arrests while in the hospital in the CCU?

K: Not to my knowledge. Let's say I didn't answer a code for the previous couple of weeks but I only work one shift and I'm off two days a week so it's possible. However, in CCU, codes are handled differently. The nursing supervisor would handle it but the CCU crash carts are not locked. They never bother to lock them because they never leave CCU.

S: Are the crash carts kept out in the halls?

$K: \quad$ No they are kept in a separate room over behind the nursing station.

S: Could he have gone and looked at it?

K: You would have to go out of your way to see it. You could, yes. A patient could if he knew what he was looking for and went out of his way. He could, yes, by accident.

S: But he was admitted directly from ER to CCU?

K: Correct.

S: And from CCU directly to the ward room?

K: Yes. And then he was on nasal oxygen, so this would have limited how far he could have gone. We use two lengths of tubing so they can get as far as their bathroom and that's it. I seriously doubt if he would have taken his oxygen off. He was a little concerned about being short of breath. He was a little hyper.

S: Could you see the nurse's stopwatch?

K: No. I was down on the floor working on him and I looked 
over and could only see the top half of the nurse standing over behind the crash cart. She held the clipboard so I couldn't see the top of it, but I didn't make an effort to look at it. I just glanced over for a second. I later asked her about it. In fact, on another code a couple of days later, I noticed she used one. I didn't know that she had used one.

S: Was there any verbal mention of the stopwatch during the arrest?

K: No. The only thing is that once in a while-and I'm now drawing more on general knowledge than specifics-they will ask how far we are into the code. It's only asked after we have been into the code for twenty or twenty-five minutes. I have thought that it was part of the decision making of the running M.D.'s as to whether to continue the code or not.

S: Was there a verbal discussion about the lock on the crash cart and the scissors?

K: Not a word said. I was pumping and looked over and saw that she was having trouble. She was just frantically turning [the lockl. Instead of bending back and forth like this, she was tuming. So rather than instruct her as to how, I carry suture scissors, so I just reached into my pocket and handed it [the scissors] to her like that. Very quickly. She just grabbed them and shoved them into the lock and twisted them. To the best of my knowledge there was not a word said. Not even "here." It was just done very quickly.

S: And the stopwatch, could he have seen it in CCU during an arrest?

K: No, because in CCU they have code clocks on the wall which begin counting as soon as the alarm goes off.

S: Have you read a lot about NDEs?

K: No, not really. I may have glanced through a few articles on it but they are usually such a religious thing and I'm not oriented towards reading this sort of thing.

S: So he volunteered this to you? 
K: Yes. I just made myself available, like, "I' $m$ here if you want to talk to me." I didn't see him after that and he died a few days later. It really didn't make a real impact on me and it was just one of those things you file in the back of your mind although it was interesting.

If Don's statements about the resuscitation and NDE are correct (and I have no reason to believe that they are not), then this patient could recall at least two specific events that had taken place during his crisis that Don could verify. These events were the twisting open of the aluminum lock on the crash cart with a pair of scissors and the use of a stopwatch to time the resuscitation by a nurse in the corner of the room. As best as can be determined, neither of these events could have been physically seen by the near-death patient who had an oxygen mask and "bag" over his face at the time. Moreover, neither of these events were verbally discussed at the time by people in the room. How, then, could this man have known about these occurrences? He claims to have actually "seen" them from a detached position near the ceiling of his room. Could this have really occurred and, if so, how?

Obviously, these questions cannot be answered on the basis of this one anecdotal account of an NDE. This case demonstrates, however, a method by which the accuracy of certain aspects of the NDE may be checked. If details in the NDE are found to be accurate, then these details may be analyzed using the scheme outlined in Figure 1. In my book, Recollections of Death: A Medical Investigation (Sabom, in press), I examine thirty-six NDEs using this scheme. The results of this analysis are then interpreted in the light of other scientific research dealing with the nature and interaction of the human mind and brain. I believe that through research such as this that the controversy described in the beginning of this paper between the near-death survivor who claims his NDE was "real as hell" and the skeptical scientist who steadfastly maintains that these experiences are a mere "fantasy of death" will begin to be resolved.

\section{NOTES}

1. Personal Communication: Near-death survivor.

2. Personal Communication: Near-death survivor.

\section{REFERENCES}

Blacher, R. S. To sleep, perchance to dream. ... Journal of the 
American Medical Association, 1979, 242, 2291.

Moody, R. A., Jr. Life After Life. Covington, Ga.: Mockingbird Books, 1975.

Sabom, M. B. Recollections of Death: A Medical Investigation. New

York: Harper and Row, in press (to be published, December, 1981).

Requests for reprints to:

Dr. Michael B. Sabom

V. A. Medical Center

1670 Clairmont Road

Decatur, Georgia 30033 